\author{
Ana Maria Paulino Comparini \\ (Universidade de Franca - UNIFRAN, \\ Fundação Educacional de Ituverava - FEI) \\ Lisângela Aparecida Guiraldelli \\ (Fundação Educacional de Ituverava - FEI) \\ Edson Rosa Francisco de Souza \\ (Universidade Estadual Paulista \\ Câmpus de São José do Rio Preto - UNESP)
}

\title{
Referência cruzada e concordância oracional no estudo de transparência e opacidade em línguas indígenas do Brasil ${ }^{*}$
}

\begin{abstract}
This paper aims at analyzing, from the perspective of the Functional Discourse-Grammar (Hengeveld and Mackenzie 2008), cross reference and agreement in the study of transparency and opacity in the indigenous languages of Brazil, taking into account the co-occurrence or not of personal mark in a verb with pronominal expression of subject argument, the scope relations between referential and agreement markers and the levels of grammar organization in which they operate in order to verify possible functional or formal motivations that lead the subject argument to be expressed sometimes pronominally sometimes with double marking (pronoun and affix).

KEYWORDS: Cross reference; Agreement; Transparency; Opacity; Functional Discourse-Grammar.
\end{abstract}

RESUMO: O objetivo deste trabalho é analisar, com base na perspectiva teórica da Gramática DiscursivoFuncional (Hengeveld e Mackenzie 2008), a referência cruzada e a concordância oracional no estudo da transparência e opacidade em um conjunto de línguas indígenas do Brasil, levando-se em consideração a coocorrência ou não da marca de pessoa no verbo com a expressão pronominal do argumento sujeito, as relações de escopo entre os marcadores referenciais e os marcadores de concordância oracional e os níveis de organização da gramática em que operam, com vistas a verificar possíveis motivações funcionais ou formais que levam o argumento sujeito a ser expresso ora apenas pronominalmente ora com dupla marcação (pronome e afixo).

PALAVRAS-CHAVE: Referência cruzada; Concordância oracional; Transparência; Opacidade; Gramática Discursivo-Funcional.

* Gostaríamos de agradecer aos colegas Rogério Ferreira, Valéria Cardoso, Pilar Valenzuela, Kristine Stenzel, Odileiz Sousa Cruz, Gabriel Araújo, Hein van der Voort, Alexandra Aikhenvald, Rosana Oliveira e Gláucia Cândido, especialistas em descrição de línguas indígenas, por responderem gentilmente ao questionário de checagem e verificação de dúvidas sobre as línguas que compõem a amostra de investigação do artigo. A ajuda de todos foi muito importante para o esclarecimento de pontos cruciais sobre as línguas indígenas. É claro que os problemas de análise que ainda persistirem no trabalho são de nossa inteira responsabilidade. 


\section{Introdução}

O objetivo do trabalho é analisar, com base nos postulados teóricos da Gramática Discursivo-Funcional (Hengeveld e Mackenzie 2008), doravante GDF, a referência cruzada e a concordância oracional no que se refere à transparência e à opacidade em línguas indígenas do Brasil, tendo em vista a coocorrência da marca de pessoa no verbo com a expressão pronominal do argumento sujeito, a ordenação dos marcadores de referência e de concordância oracional e os níveis e as camadas de organização da gramática em que cada um desses fenômenos opera.

Mais especificamente, o propósito é investigar as razões funcionais e formais que levam o argumento sujeito da oração a ser expresso ora de forma apenas pronominal, sem necessitar de nenhum afixo verbal para marcar a noção de pessoa, ora de forma duplamente marcada, isto é, por meio de referência cruzada (pronome e afixo). Os exemplos em (1a-b) ilustram a ocorrência desse fenômeno no português brasileiro:

(1) a. Eu comprei uma linda casa.

b. Ø Comprei uma linda casa.

Como se pode observar em (1a), o sujeito é expresso por meio do pronome "eu" e do sufixo verbal de primeira pessoa do singular “-i”. Segundo Hengeveld (2011), uma língua possui um sistema de referência cruzada quando a marcação afixal de pessoa, no caso do português brasileiro, é suficiente para marcar o argumento sujeito da oração, sem que seja necessário expressá-lo também na forma lexical/pronominal. ${ }^{1}$ Nesse sentido, se o afixo de pessoa e número, como em (1b), pode funcionar sozinho, como expediente gramatical para marcar o argumento sujeito da oração, é porque esse morfema cumpre função referencial e corresponde, nos termos da GDF, a um subato referencial. Em outros termos, se a dupla marcação do argumento sujeito na língua não for um sistema opcional, não se pode dizer que a língua possui referência cruzada.

Dessa forma, a presença de referência cruzada no português brasileiro mostra que a língua é opaca quanto à expressão do argumento sujeito, pois se observa que há duas unidades referenciais, no nível interpessoal, que correspondem a uma única unidade semântica no nível representacional. Tem-se, nesses casos, em termos de pareamento entre forma e significado, uma relação de dois-para-um entre as camadas do nível interpessoal e as do nível representacional, e não uma relação de um-para-um entre forma e significado, que seria concebido como um caso de transparência.

O inglês, por exemplo, é uma língua que não permite a expressão de argumento sujeito apenas por meio de morfema desinencial, ${ }^{2}$ pois o sistema de flexão verbal é destituído de marcas distintivas para todas as pessoas do discurso, mantendo especificações apenas na primeira e na terceira pessoas do singular (no caso dos verbos irregulares), razão pela qual, para evitar ambiguidade quanto à referência, a posição de argumento sujeito é obrigatoriamente preenchida por um argumento pronominal.

\footnotetext{
${ }^{1}$ Tomamos como sinônimos os termos "lexical" e "pronominal" referentes ao argumento sujeito.

${ }^{2}$ Neste artigo, utilizaremos de forma intercambiável os termos "morfema", "afixo" e "desinência" para fazer menção ao argumento sujeito (noção de pessoa) que é mercado no verbo.
} 
Em termos morfossintáticos, o holandês é semelhante ao inglês, pois a dupla marcação de argumento sujeito (pronominal e flexional) é sempre obrigatória na língua, de modo que, se o argumento sujeito não for expresso, a sentença será considerada agramatical, conforme veremos mais adiante. Nesse sentido, segundo Hengeveld (2012), tem-se um caso de concordância oracional, que se diferencia do fenômeno de referência cruzada, justamente porque o primeiro não contribui para o significado da oração, já que constitui uma cópia de informação de um sintagma lexical a outra unidade morfossintática, como, por exemplo, o sintagma verbal.

Segundo Dik (1989; 1997), Hengeveld e Mackenzie (2008) e Hengeveld (2011), como as línguas constituem um instrumento de comunicação, é de se esperar que elas sejam extremamente transparentes na expressão de suas relações gramaticais, no sentido de "apresentar uma relação de um-para-um entre significado e forma" (Hengeveld, 2011:1). No entanto, segundo Hengeveld, a maioria das línguas não é totalmente transparente, e muitas delas apresentam inclusive um elevado grau de opacidade (quando a relação entre significado e forma é de muitos-para-um). Essa observação leva, conforme Hengeveld, a duas questões: (i) há alguma sistematicidade no modo como as línguas perdem a transparência, ou seja, adquirem características opacas? (ii) como essa sistematicidade pode ser explicada? Para tentar responder a esses questionamentos, o autor assinala que é necessário comparar diferentes línguas, a fim de determinar se existem relações implicacionais, em termos de transparência e opacidade, entre as formas usadas pelas línguas para codificar as relações gramaticais.

Feitas as observações iniciais sobre referência cruzada e os conceitos teóricos de transparência e opacidade discutidos por Hengeveld e Mackenzie (2008), Hengeveld (2011; 2012) e Leufkens (2013), a nossa expectativa com relação às línguas da amostra é a de que os marcadores referenciais ocupem, em termos de ordenação morfossintática, uma posição mais próxima ao verbo, por serem elementos de conteúdo pleno, enquanto os marcadores de concordância oracional, por não afetarem diretamente o sentido do verbo, como veremos adiante, tendam a ocupar uma posição periférica em relação a ele.

$\mathrm{O}$ intuito é de que esses procedimentos permitam estabelecer não apenas o grau de transparência entre essas línguas com relação à expressão de argumento sujeito, mas também verificar a natureza morfossintática da ordenação desses marcadores em relação ao verbo, uma vez que a presença de morfemas cumulativos, em que um afixo serve a mais de uma categoria, além de não permitir verificar as relações de escopo entre as categorias gramaticais presentes no verbo, indicam contextos de opacidade.

Para cumprir esses objetivos, o artigo se organiza da seguinte maneira: a seção 2 apresenta uma breve discussão sobre os conceitos de transparência e opacidade na GDF; a seção 3 trata da referência cruzada e concordância oracional na GDF; a seção 4 traz a metodologia e a amostra de línguas indígenas analisadas no trabalho; a seção 5 apresenta a análise sobre a referência cruzada e a concordância oracional nas línguas indígenas da amostra, seguida, na seção 6, de algumas generalizações acerca do grau de transparência das línguas indígenas. Por fim, as considerações finais encerram o estudo. 


\section{Princípios teóricos: transparência e opacidade na GDF}

A transparência pode ser definida, segundo Hengeveld (2011), Leufkens (2013) e Hengeveld e Leufkens (inédito), como uma relação de um-para-um entre significado e forma, o que significa que uma unidade pertencente a um nível de organização linguística corresponde sempre a uma unidade em um dos outros níveis de organização ${ }^{3}$ da GDF, assim representado de forma esquemática na figura 1 a seguir.

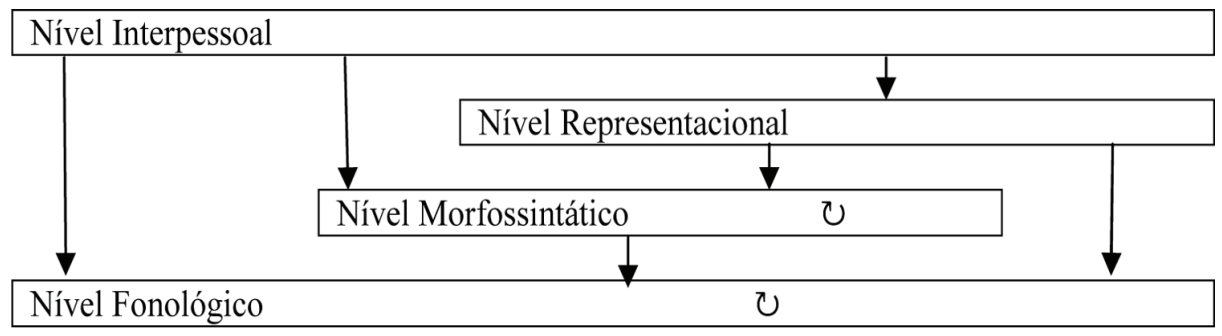

Figura 1: Interações entre níveis e camadas (Hengeveld e Leufkens, inédito)

Há interações entre todos esses níveis, ${ }^{4}$ que operam de cima para baixo (numa direção top-down), como ilustrado por meio das setas na figura 1. De acordo com Hengeveld e Leufkens (inédito), os níveis interpessoal e representacional se ocupam das questões de significado, enquanto os níveis morfossintático e fonológico se ocupam dos diferentes aspectos de codificação (forma). Já o símbolo ' $U$ ' indica as possíveis operações que podem ocorrer no interior dos níveis morfossintático e fonológico, que são formalmente motivadas. Essas operações, segundo os autores, não têm uma contrapartida interpessoal ou representacional, ou seja, elas possuem uma forma, mas não têm nenhum significado, fato que contribui, pois, para a opacidade de uma língua. Um exemplo é o uso de expletivos. Em inglês, o "it" em "It's rainning" (Está chovendo), é obrigatório na língua, pois a posição de sujeito é sempre preenchida.

Ao comparar o grau de transparência do holandês, kharia, quechua, malaio do Sri Lanka e esperanto, por meio da observação de um conjunto de propriedades linguísticas, que contempla todos os níveis, Hengeveld (2011) verificou que o holandês é mais opaco do que as demais línguas por estar mais propenso a sofrer algum tipo de rearranjo morfossintático com vistas à economia de formas linguísticas.

Já o esperanto 5 (Jansen 2011), que é uma língua artificial, também apresenta, segundo Hengeveld (2011), traços de opacidade, em especial no que tange à codificação de relações gramaticais e à concordância verbal. Em tese, isso não deveria acontecer, segundo o autor, já que o esperanto foi desenvolvido para ser altamente transparente, isto é, para ser uma língua de contato, para facilitar a interação entre os usuários.

${ }^{3}$ Essa relação de um-para-um não precisa necessariamente envolver todos os níveis ao mesmo tempo.

${ }^{4}$ Para mais informações sobre o modelo hierárquico da GDF, confira Camacho et al. (neste volume).

${ }^{5} \mathrm{O}$ esperanto foi desenvolvido por Ludwik Zamenhof, em 1887, com o objetivo de oferecer às pessoas com diferentes línguas maternas uma ferramenta de fácil comunicação 
Para Leufkens (2013: 323), a noção de "transparência na gramática é uma vantagem do ponto de vista cognitivo". Ou seja, a autora ressalta que "os mapeamentos de umpara-um são mais fáceis de aprender, ao passo que a aquisição de estruturas opacas é mais lenta". Sobre esse aspecto, Leufkens cita como exemplo a aquisição tardia de gênero gramatical em holandês, que só é totalmente dominado pelas crianças por volta dos oito anos de idade (Blom et al. 2008 apud Leufkens 2013). Assim, o que podemos depreender das observações de Leufkens é que, aparentemente, a transparência constitui o ponto de partida da língua, quanto ao processo de aquisição da gramática, enquanto a opacidade, que é o ponto de chegada, e só é adquirida mais tardiamente.

A opacidade é definida, segundo Hengeveld (2011) e Mulder (2013), como uma relação de um-para-muitos entre os níveis de organização da GDF, ou então como uma relação de um-para-zero que ocorre quando algum material é inserido nos níveis mais baixos sem apresentar nenhuma contraparte nos níveis mais altos da gramática.

A esse respeito, Leufkens (2013) assinala que a transparência linguística pode ser violada de três maneiras: (i) por redundância (figura 2), que compreende as relações que se estabelecem entre um significado e duas ou mais formas, (ii) por desintegração de domínio (figura 3), que ocorre quando se rompe a integridade das unidades formais, como, por exemplo, nos casos de infixação, em que um infixo (morfema) segmenta a base verbal (ou nominal) em duas partes, provocando, assim, um tipo de descontinuidade no nível morfossintático; e (iii) por categorias formalmente motivadas (figura 4), que inclui, segundo a autora, todas as formas e operações formais que não têm qualquer contrapartida ou motivação pragmática ou semântica. Novamente, os elementos expletivos são um bom exemplo para ilustrar esse tipo de operação.

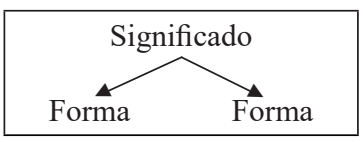

Figura 2: Redundância

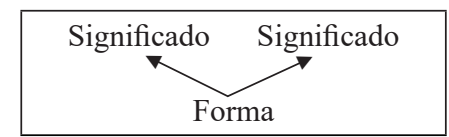

Figura 3: Desintegração de domínio

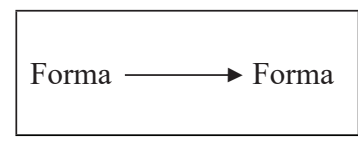

Figura 4: Categorias formais

Fonte: Formas de violação da transparência linguística (Leufkens 2013: 325)

Na próxima seção, discutimos como se processam as relações de transparência e opacidade com relação aos níveis e às camadas de organização da GDF, a partir da observação de dois fenômenos específicos: referência cruzada e concordância oracional.

\section{Relações de transparência e opacidade e os fenômenos de referência cruzada e concordância oracional na GDF}

Segundo Hengeveld (2011), o grau de transparência de uma língua pode ser mapeado em todos os níveis da gramática. Para o autor, as relações entre os níveis podem ser agrupadas com relação ao seu ponto final de chegada, no sentido de que o que passa para o nível morfossintático é resultado cumulativo dos níveis interpessoal e representacional e, consequentemente, o que passa para o nível fonológico é resultado cumulativo dos níveis interpessoal, representacional e morfossintático. Esse sistema de organização descendente da GDF permite identificar três tipos de agrupamentos (Hengeveld 2011): interpessoal-representacional; interpessoal/representacional-morfossintático; interpessoal/ representacional/ morfossintático - fonológico. 
Com relação ao alinhamento entre os níveis da GDF, no caso da referência cruzada, a língua apresenta duas unidades referenciais no nível interpessoal que correspondem, como já dissemos, a uma única unidade semântica (indivíduo) no nível representacional, estabelecendo, desse modo, uma relação de dois-para-um entre significado e forma. Tal relação é classificada por Hengeveld (2011) como opaca, como se vê na figura (5). Segundo Leufkens (2015), na referência cruzada, a relação de opacidade pode ainda ser observada entre o nível representacional e o nível morfossintático, uma vez que uma única unidade semântica é codificada por dois dispositivos gramaticais (um sintagma nominal e um sufixo), estabelecendo, assim, uma relação de um-para-dois entre significado e forma, como na figura (6) a seguir:

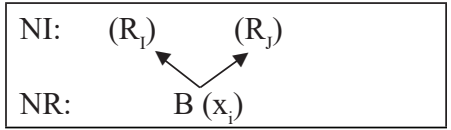

Figura 5: Opacidade entre NI e NR

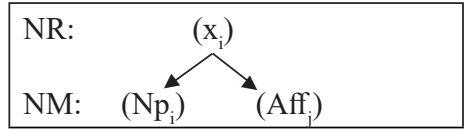

Figura 6: Opacidade entre NI e NR

No entanto, se o argumento sujeito é expresso por meio de um único marcador referencial (que pode ser o pronome ou o afixo verbal), numa relação de um-para-um entre significado e forma, a língua é, segundo Hengeveld (2011), transparente.

Diferentemente da referência cruzada, quando a dupla marcação do argumento sujeito é obrigatória, como acontece no inglês, e não há possibilidade de o argumento sujeito ser expresso na língua apenas por um afixo, o que se tem é um caso de concordância, no qual uma propriedade do argumento sujeito pronominal é copiada em outra unidade da oração. Nesse caso, para Hengeveld, a marcação de pessoa no verbo não é uma unidade referencial por si só, o que justifica o fato de a concordância oracional ser definida na GDF como um fenômeno morfossintático, uma operação puramente formal, pois não apresenta uma contraparte semântica ou pragmática.

A figura 7 mostra como se processa o fenômeno da concordância oracional com relação às camadas do Nível Morfossintático:

$$
\text { NM: }\left(\mathrm{Np}_{\mathrm{i}}: 1 . \mathrm{PL}\left(\mathrm{Np}_{\mathrm{i}}\right)\right)_{\mathrm{Sbj}} \longrightarrow\left(\mathrm{Np}_{\mathrm{i}}: 1 . \mathrm{PL}\left(\mathrm{Np}_{\mathrm{i}}\right)\right)_{\mathrm{Sbj}}\left(\mathrm{Aff}_{\mathrm{i}}:<1 . \mathrm{PL}>\left(\mathrm{Aff}_{\mathrm{i}}\right)\right)
$$

Figura 7: Relação de opacidade entre as camadas do NM

Baseando-se em Siewierska (1999), que também analisou o fenômeno da concordância de pessoa em diversas línguas, Hengeveld (2012) lista o turco como um caso ambíguo de referência cruzada/concordância (Siewierska 1999). Segundo o autor, com base em Özturk (2002), quando o sujeito pronominal no turco não é expresso na oração, a marca de pessoa no verbo é considerada referencial. Caso o argumento sujeito seja expresso pronominalmente, considera-se o afixo de pessoa uma marca de concordância. Hengeveld (2012), por outro lado, postula que, em ambas as circunstâncias (na ausência ou presença da marcação de pessoa), a noção de pessoa no verbo opera da mesma forma, estabelecendo uma relação de concordância com o argumento sujeito. Os exemplos (2a) e (2b), do turco, ilustram a análise do autor:
a. Ben konus-ur-ken,
o gul-uyor-du- $\varnothing$.
I talk-AOR-SIM s/he laugh-PROGR-PST-3SG 'Enquanto eu estava falando, ele/a estava rindo.' 


\section{b. Konus-ur-ken, gul-uyor-du- $\boldsymbol{\varnothing}$. talk-AOR-SIM laugh-PROGR-PST-3SG 'Enquanto falava, ele/a estava rindo.'}

Segundo Hengeveld (2012: 473), a oração subordinada em (2b) mostra que, mesmo na ausência de um marcador de pessoa no verbo, o argumento sujeito pode não ser expresso pronominalmente, principalmente se esse argumento exercer a função pragmática de tópico dado, ao passo que, em (2a), por se tratar de um contexto em que o argumento sujeito exerce a função de tópico contrastivo, ele precisa ser necessariamente expresso (Ben "eu”,; o "elelela"). Para o autor, é um tipo de concordância que se estabelece a partir de informações fornecidas pelo componente contextual, fato que leva o autor a definir esse tipo como marcadores de concordância contextual.

Outro aspecto importante que, conforme Hengeveld e Mackenzie (2008) e Hengeveld (2012), ajuda a distinguir entre marcador referencial e marcador de concordância oracional é a ordenação desses marcadores em relação ao verbo.

Segundo Hengeveld (2012: 469), no processo de organização morfossintática da GDF, o codificador morfossintático passa por algumas etapas de ordenação para construir a representação morfossintática subjacente: (i) ordenação hierárquica, (ii) ordenação não-hierárquica, (iii) inserção de dummy, e (iv) concordância.

Para o autor, na ordenação hierárquica, que se baseia em relações de escopo, alocam-se elementos que estão em uma relação hierárquica em determinada posição respeitando-se o sentido descendente, ao passo que na ordenação não-hierárquica, que se baseia em questões de alinhamento, ordenam-se elementos que estão em uma relação configuracional, tais como a de predicado-argumento e a de núcleo-modificador, com base em suas propriedades pragmáticas, semânticas e/ou morfossintáticas, que podem variar a depender da língua. A colocação de um dummy envolve, por exemplo, o preenchimento de uma posição obrigatória não preenchida nas etapas anteriores. Já a concordância envolve a colocação de elementos que expressam uma variedade de traços que são copiados de uma unidade morfossintática para outra unidade.

Os padrões, nos quais são inseridos os vários elementos listados aqui, são construídos de forma dinâmica. Eles começam, segundo Hengeveld (2012), como combinações simples de pontos de ancoragem absoluta, os quais, dependendo da língua, consistem, no máximo, na posição inicial $\mathrm{P}^{\mathrm{I}}$, na segunda posição $\mathrm{P}^{2}$, na posição medial $\mathrm{P}^{\mathrm{M}}$ e na posição final $\mathrm{P}^{\mathrm{F}}$, Após o preenchimento, podem-se expandir as posições absolutas com posições relativas $\left(\mathrm{P}^{\mathrm{M}+1}, \mathrm{P}^{\mathrm{F}-1}\right.$ etc. $)$.

A ideia de Hengeveld (2012), ao olhar para a ordenação de elementos hierárquicos e não-hierárquicos, é a de que os marcadores de pessoa que expressam referência cruzada tendem a ser alocados em uma posição na etapa 2 (ordenação não hierárquica), uma vez que constituem elementos (argumentos) plenos de conteúdo. Já os marcadores de pessoa que expressam concordância (oracional) tendem, por sua vez, a ser alocados em uma posição na etapa 4, depois que todos os elementos plenos de conteúdo tiverem encontrado sua posição no esquema sintático. Como consequência, espera-se, conforme o autor, que os marcadores de concordância oracional geralmente ocupem posições mais distantes com relação ao núcleo verbal, enquanto os marcadores referenciais tendam a posicionar-se em posições mais próximas, ao participarem da ordenação configuracional dos elementos que compõem o quadro de predicação. 
Assim sendo, a previsão é a de que os afixos de concordância (AGR-Agreement), como ilustrado em (3), e os afixos de referência (REF-Reference), como mostrado em (4), ocupem as seguintes posições com relação a outros elementos que participam morfologicamente da formação do predicado verbal:

(3)
a. V-TAM-AGR
(4)
a. V-REF-TAM
b. AGR-TAM-V
b. TAM-REF-V
c. AGR-V-TAM
c. TAM-V-REF
d. TAM-V-AGR
d. REF-V-TAM
e. *V-AGR-TAM
e. */? V-TAM-REF
f. *TAM-AGR-V

Cabe destacar que a proposta acima é mais adequada às línguas em que se exprimem as informações de tempo, aspecto e modo (TAM) e pessoa com base em afixos; caso contrário não há garantia de que as previsões em (3) e (4) sirvam, igualmente, para as línguas com morfologia isolante ou flexional, por exemplo. Trata-se de uma proposta que, de certa forma, recupera as predições de Bybee (1985), ao propor, a partir de um estudo tipológico, que a ordem de ocorrência dos afixos nas línguas tende a ser: valência $<$ voz $<$ aspecto $<$ tempo $<$ modo $<$ concordância de pessoa/número.

Ainda segundo as previsões listadas em (3) e (4), Hengeveld (2012) assinala que as línguas que expressam as categorias de TAM e AGR/REF em lados opostos ao predicado, como em (3c-d) e (4c-d), não podem ser usadas para confirmar ou rejeitar a hipótese de ordenação e de manutenção das relações de escopo entre tais categorias, uma vez que não há como verificar as relações de escopo entre elas. Por essa razão, como pretendemos checar a proposta de Hengeveld, como forma de distinguir a referência cruzada da concordância oracional, essas ordenações serão descartadas.

\section{Amostra de línguas indígenas e procedimentos metodológicos}

A amostra é composta por 16 línguas indígenas, distribuídas entre as principais famílias linguísticas, com vistas a atender à diversidade linguístico-cultural das línguas indígenas faladas no Brasil, incluindo as línguas isoladas (sem classificação). Vale destacar que não utilizamos o critério da proporcionalidade entre o número de línguas de cada família e tronco linguístico para organizar a amostra, pois esse procedimento demandaria a análise de um número muito grande de línguas, o que fugiria dos propósitos deste estudo. Nesse sentido, além de contemplar a diversidade linguístico-cultural das línguas indígenas do Brasil, buscamos também selecionar apenas línguas que apresentassem informações (suficientes) sobre a expressão do argumento sujeito ou então sobre o fenômeno de referência cruzada, haja vista que nem todas as gramáticas disponíveis trazem referências diretas desses tópicos, o que inviabiliza o trabalho. 
A amostra de línguas indígenas desta pesquisa é composta como segue:

Quadro 1: Amostra de línguas indígenas do Brasil.

\begin{tabular}{|c|c|c|c|}
\hline Língua & Filiação Genética & Localização & Referências \\
\hline Apinajé & Tronco Macro Jê & Planalto central do Brasil & Oliveira $(2004 ; 2014)$ \\
\hline Apurinã & Família Maipuran & Sul do Amazonas, norte do Acre & Facundes (2000) \\
\hline Dâw & Família Maku & Alto Rio Negro (Amazonas) & Martins (2004) \\
\hline Ingarikó & Família Karib & $\begin{array}{l}\text { Fronteira entre Brasil, Venezuela } \\
\text { e Guiana Inglesa }\end{array}$ & Sousa Cruz (2005) \\
\hline Jarawara & Família Arawá & Casa Nova (Amazonas) & Dixon (2004) \\
\hline Kaiowá & Família Tupi-Guarani & Mato Grosso do Sul & Cardoso (2008) \\
\hline Kamaiurá & Família Tupi-Guarani & Rio Xingu, Mato Grosso & Seki (2000) \\
\hline Kanoê & Família Kanoê & $\begin{array}{l}\text { Sul de Rondônia (Brasil), } \\
\text { fronteira com a Bolívia }\end{array}$ & Bacelar (2004) \\
\hline Kotiria & Família Tukano & $\begin{array}{l}\text { São Gabriel da Cachoeira } \\
\text { (Amazonas) }\end{array}$ & Stenzel (2013) \\
\hline Kwaza & Língua isolada & Norte de Vilhena (Rondônia) & Voort (2004) \\
\hline Matis & $\begin{array}{l}\text { Família Pano do } \\
\text { Norte }\end{array}$ & Médio Ituí (noroeste amazônico) & Ferreira (2005) \\
\hline Matsés & Família Pano & Brasil e Peru & Fleck (2003) \\
\hline Sabanê & Família Nambikwara & $\begin{array}{l}\text { Cidade de Vilhena, no Estado de } \\
\text { Rondônia, Sul do Amazonas }\end{array}$ & Araújo (2004) \\
\hline Shanenawa & $\begin{array}{l}\text { Tronco Pano-Takana } \\
\text { Família Pano }\end{array}$ & $\begin{array}{l}\text { Município de Feijó (Norte do } \\
\text { Estado do Acre) }\end{array}$ & Cândido (2004) \\
\hline Tariana & Família Arawak & Rio Vaupés (Amazonas) & Aikhenvald (2003) \\
\hline Xavante & $\begin{array}{l}\text { Família Jê } \\
\text { Tronco Macro-Jê }\end{array}$ & Leste do estado de Mato Grosso & Oliveira (2007) \\
\hline
\end{tabular}

Os dados sobre a expressão do argumento sujeito, aqui analisados a partir dos preceitos teóricos da GDF (Hengeveld e Mackenzie 2008; Hengeveld 2011; 2012), foram coletados em gramáticas descritivas de línguas indígenas disponíveis em bibliotecas virtuais. Não houve, portanto, pesquisa de campo com as línguas da amostra, no entanto, para averiguar a pertinência e a validade de nossa análise, recorremos à checagem de dados junto aos autores das gramáticas das línguas. $\mathrm{O}$ intuito deste procedimento, implementado por meio do envio aos autores de questionários com perguntas e dados direcionados especificamente para os fenômenos aqui investigados, é minimizar a realização de análises equivocadas de dados. Cabe ressaltar ainda que as glosas originais dos exemplos nem sempre são mantidas, uma vez que os dados coletados nas gramáticas são reinterpretados à luz da GDF e das convenções de glosamento interlinear morfema-por-morfema de Leipzig Glossing Rules (2016). 
Hengeveld (2011) utiliza 14 critérios para avaliar o grau de transparência de um grupo de línguas. Neste estudo, porém, mediremos a transparência das línguas indígenas da amostra considerando apenas a presença ou não de referência cruzada e concordância oracional em cada uma das línguas, com o intuito de verificar quais línguas indígenas da amostra são mais transparentes ou mais opacas no tocante à expressão do argumento sujeito e qual das propriedades analisadas, referência cruzada ou concordância oracional, estaria mais suscetível de ocorrer com maior frequência, além de levantar possíveis explicações para o quadro de transparência/opacidade dessas línguas.

Em função disso, consideramos também, como critério para organizar a amostra de investigação, línguas com diferentes tipos de morfologia, uma vez que tal característica pode, segundo Hengeveld (2012), influenciar o grau de transparência das línguas, tendo em vista serem as línguas isolantes as mais transparentes.

\section{Resultados}

\subsection{Referência cruzada e concordância oracional nas línguas indígenas da amostra}

A tabela 1, a seguir, ilustra o modo de organização das línguas indígenas da amostra com relação à presença/ausência de referência cruzada e concordância oracional. Conforme já discutido, quando a língua expressa o argumento sujeito por meio do sistema de referência cruzada, dizemos que ela é opaca. O mesmo raciocínio se aplica à concordância oracional, isto é, quando a informação de pessoa é replicada na estrutura oracional, acionando, portanto, mais de um dispositivo morfossintático para marcar uma mesma informação gramatical, dizemos que a língua é também opaca.

A análise dos casos de referência cruzada e concordância oracional nas línguas da amostra permite identificar três subgrupos distintos de línguas, a saber: (i) as que apresentam sistema de referência cruzada, (ii) as que apresentam sistema de concordância oracional, e (iii) as que não apresentam nem referência cruzada nem sistema de concordância oracional (mas referência simples), conforme tabela a seguir:

Tabela 1: Referência cruzada e concordância oracional nas línguas indígenas da amostra

\begin{tabular}{l|c|c}
\cline { 2 - 3 } & \multicolumn{2}{c}{ Fenômenos linguísticos } \\
\cline { 2 - 3 } & Referência cruzada & Concordância oracional \\
\hline Apinajé & + & - \\
\hline Apurinã & + & - \\
\hline Jarawara & + & - \\
\hline Kotiria & + & - \\
\hline Kwaza & + & - \\
\hline Tariana & + & - \\
\hline Matsés & + & - \\
\hline Kaiowá & + & - \\
\hline Kamaiurá & + & - \\
\hline Xavante & + & - \\
\hline
\end{tabular}




\begin{tabular}{l|c|c}
\hline Kaiowá & - & + \\
\hline Kanoê & - & + \\
\hline Kaiowá & - & - \\
\hline Matsés & - & - \\
\hline Dâw & - & - \\
\hline Ingarikó & - & - \\
\hline Kamaiurá & - & - \\
\hline Matis & - & - \\
\hline Sabanê & - & - \\
\hline Shanenawa & & - \\
\hline
\end{tabular}

Entre as línguas que compõem o primeiro subgrupo estão apinajé, apurinã, jarawara, kotiria, kwaza, tariana, matsés, kaiowá, kamaiurá e xavante. Nessas línguas, a marcação de pessoa no verbo coocorre com a expressão lexical do mesmo argumento na oração, fenômeno que é também conhecido como concordância de pessoa. Vejamos:

(5) Apinajé (Oliveira 2005: 161)

$\begin{array}{llll}\text { Kot } & \text { paj } & \text { ari } & \text { ic-krĩ } \\ \text { IRLS } & \text { 1SG.IRLS } & \text { ficar } & 1 \text { sG-sentar }\end{array}$

Eu ficarei sentado.'

No exemplo (5), a marca de pessoa no verbo ic- (eu) coocorre com a expressão lexical do argumento sujeito paj (eu), caracterizando, assim, um caso de referência cruzada, segundo Hengeveld $(2011 ; 2012)$ e Leufkens (2013). Observa-se o mesmo comportamento nos dados das demais línguas listadas acima, que são classificadas como opacas, uma vez que há dois subatos referenciais no nível interpessoal que correspondem a uma única unidade semântica (indivíduo) no nível representacional, fato que evidencia uma relação de opacidade entre os dois níveis.

Segundo Hengeveld (2012), o que comprova a existência de referência cruzada em uma língua, como se vê no exemplo acima, é a possibilidade de o argumento sujeito ser codificado apenas pelo morfema de pessoa. Quando isso acontece, conforme mostra o exemplo (6), não há necessidade de o argumento sujeito ser expresso também em termos pronominais, o que mostra que essas duas estratégias gramaticais constituem sistemas alternativos para marcação de sujeito nas línguas indígenas da amostra.

(6) Apinajé (Oliveira 2005: 246)

a ic-pe kenkutz̃

$\operatorname{sim} 1 \mathrm{sG}-\mathrm{COP} \quad \mathrm{N}$.

'Sim, eu sou Kengutã.'

${ }^{6}$ Para dados adicionais de mais línguas sobre ocorrência de referência cruzada, consultar o apêndice 1.

${ }^{7}$ Para a verificação de exemplos de outras línguas que comprovam a possibilidade de o argumento sujeito (ou a marcação de pessoa) ser expresso apenas pelo afixo verbal, consultar o apêndice 1 . 
No exemplo (6), a marcação de pessoa no verbo, representada aqui pelo afixo ic-, é referencial por si só, já que o argumento sujeito não precisa ser expresso lexicalmente, ou seja, o sistema de marcação do sujeito oracional nas línguas indígenas acima é opcional, podendo ser expresso por dupla marcação, quando o sujeito é expresso simultaneamente no verbo e na forma lexical, ou apenas por meio da expressão lexical, ou apenas por meio da marcação do argumento sujeito na morfologia do verbo (prefixos, infixos ou sufixos).

Segundo Hengeveld (2012), quando a marcação do sujeito é opcional nas línguas, isto é, há mais de uma forma para marcar a categoria de pessoa, então, é possível dizer que elas apresentam um sistema de referência cruzada; caso contrário, se a dupla marcação do sujeito é sempre obrigatória na oração, a tendência, conforme o autor, é a de que esse sistema seja mais bem classificado como um caso de concordância oracional.

Além desse primeiro subgrupo de línguas, que se caracteriza por apresentar um sistema de referência cruzada, identificamos, também, na amostra, outro subgrupo que apresenta um sistema de concordância oracional. Nesse caso, a categoria de pessoa é sempre obrigatoriamente marcada por afixos verbais e por pronomes. De acordo com Hengeveld $(2011 ; 2012)$ e Leufkens $(2013 ; 2015)$, a expressão obrigatória do sujeito por meio da dupla marcação é um forte argumento para o entendimento de que esse processo constitui uma operação puramente formal, que opera apenas no nível morfossintático, na qual a marca de pessoa no verbo constitui uma cópia da informação de pessoa presente no sintagma nominal. É o típico caso de operação formal que não contribui para o significado da oração (Hengeveld 2012), uma vez que não há uma contraparte dos níveis interpessoal e representacional. Trata-se apenas da reprodução da informação de pessoa, que, em outras línguas, já seria suficientemente marcada pelo sujeito pronominal, sem ser necessário replicá-la em outros pontos da estrutura oracional. Em termos de processamento cognitivo, fica evidente que esse tipo de operação demanda mais esforço do usuário da língua, uma vez que o que está em jogo nesse caso é uma motivação puramente formal, e, por essa razão, é opaco.

As línguas indígenas que integram esse segundo subgrupo são kaiowá e kanoê. $\mathrm{O}$ traço em comum entre essas duas línguas é que ambas apresentam predominantemente uma morfologia aglutinante, característica que é importante, haja vista que parece haver, segundo Hengeveld e Leufkens (inédito), uma possível correlação entre o tipo morfológico das línguas e a relação de transparência. Os autores destacam que línguas isolantes, como samoano, fongbe e teiwa, estão entre as mais transparentes da amostra de línguas analisada por eles, ao passo que as línguas aglutinantes, como west greenlandic, por exemplo, estão entre as mais opacas.Isso acontece porque, nas línguas isolantes, a relação entre significado e forma é quase sempre de um-para-um, ao passo que nas línguas aglutinantes a relação entre significado e forma pode ser de dois-para-um, indicando, assim, opacidade.

Vale ressaltar, no entanto, que não se pode conceber a classificação de línguas por tipo de morfologia de maneira estanque, pois há muitas delas que apresentam uma morfologia híbrida. Nesse contexto, as línguas fusionais ou flexionais, como o holandês, o árabe, o georgiano, que também contêm traços de morfologia aglutinante, tendem, segundo Hengeveld e Leufkens, a se colocar entre os dois extremos da escala entre transparência e opacidade. O exemplo (7) ilustra um caso de concordância oracional: 
(7) Kanoê (Bacelar 2004: 98)

$\begin{array}{lll}a j & m \tilde{o}-\tilde{o}-k \tilde{y} j & \tilde{\boldsymbol{o}}-e-r e \\ 1 \mathrm{SG} & \text { dormir-1SG-olho } & \text { 1SG-DECL-AUX } \\ \text { 'Eu } & \text { durmo.' (Lit. Eu estou dormindo) }\end{array}$

Em kanoê, a dupla marcação de sujeito é sempre obrigatória, como se vê em (7), em que o sujeito pronominal aj (primeira pessoa do singular) é empregado juntamente com a marca de pessoa no verbo õ- (primeira pessoa do singular). ${ }^{9}$ De acordo com Hengeveld (2012), sempre que se verifica esse tipo de co-ocorrência, o fenômeno é elencado como concordância oracional. O próprio Bacelar, autor da gramática kanoê, diz que "nomes e pronomes pessoais livres, na função de núcleo de sujeito, concordam por referência cruzada com pronominais flexionais presos, prefixais ou sufixais, na estrutura predicativa" (Bacelar 2001: 98), no entanto, em conformidade com a noção de referência cruzada aqui assumida, vemos que os afixos verbais empregados em kanoê, como em (7), não são referenciais por si sós, pois não evocam referentes por sí sós na língua.

Nessas línguas do segundo subgrupo, a relação de opacidade se processa no próprio nível morfossintático e não pode ser entendida como um caso de redundância, por não envolver uma unidade de significado formulada no nível representacional, codificada, no nível morfossintático, por duas formas distintas, mas por uma unidade gramatical que é, na maioria dos casos, copiada no verbo a partir de afixos.

Entre as línguas da amostra que não apresentam nem referência cruzada nem sistema de concordância oracional estão dâw, ingarikó, kamaiurá, matis, sabanê e shanenawa. Como nas línguas desse subgrupo, o argumento sujeito é, em geral, expresso pronominalmente, apresentando, portanto, um único marcador referencial (Hengeveld 2012: 474), elas são aqui classificadas como as mais transparentes da amostra analisada. Vejamos:

(8) Dâw (Martins 2004: 350)

$\begin{array}{llll}\text { Pã h dó? } \quad x r d-\tilde{\varepsilon} h & m^{2} \tilde{\tilde{u}} j^{?} \\ \text { 1sG } & \text { MOV? } & \text { passar-NEG } & \text { 2SG.OBL } \\ \text { 'Eu não vou levar você.' } & \end{array}$

(9) Kamaiurá (Seki 2000: 319)

$\begin{array}{lll}\text { yrypary-a a-pyhyk } & \text { mokõj } \\ \text { cesta-N } & \text { 1sG-pegar } & \text { dois } \\ \text { 'Eu pego duas cestas.' } & \end{array}$

${ }^{8}$ Para mais exemplos da língua Kanoê sobre a expressão do argumento sujeito, verificar o apêndice 2.

9 Segundo Bacelar (2004: 170), a depender da classe de sintagmas verbais, a relação de concordância entre o sujeito pronominal e a estrutura verbal, pode envolver três situações: (i) verbos com flexão pessoal prefixal (cuja concordância é restrita à relação com o sujeito), (ii) verbos com flexão pessoal após a raiz verbal (que apresentam um pronome sufixal preso e outra marca no próprio verbo da oração), e (iii) verbos com flexão pessoal que apresentam um pronome sujeito e uma marcação no auxiliar. No entanto, apesar de haver diferenças no modo de expressão do sujeito, o que se verifica nos dados do anexo 2 é sempre uma relação de opacidade, tendo em vista que o argumento sujeito é sempre expresso pronominalmente (1SG aj, 2SG mi, 3SG oj, 1PL ajte, 2PL mite, 3PL ojte) e também por meio de afixo verbal, que se pode se acoplar ao verbo principal ou então a um verbo auxiliar (TAM). 
Em (8), exprime-se o argumento sujeito por meio de forma pronominal, como ilustram os negritos. Já em (9), o argumento sujeito é marcado pelo prefixo verbal.

É possível estabelecer, nesse terceiro grupo de línguas, uma correlação, ainda que parcial, entre o tipo morfológico da língua e o seu grau de transparência, já que as línguas que compõem esse subgrupo apresentam, na sua maioria, uma morfologia mista, isto é, elas têm traços de morfologia aglutinante mas, também, apresentam traços de morfologia isolante, o que poderia contribuir para o fato de essas línguas serem, entre todas aquelas analisadas, as mais transparentes da amostra. Mesmo nos casos em que a língua é basicamente aglutinante, observa-se que a relação entre forma e sentido é quase sempre de um-para-um, o que novamente corrobora a nossa análise.

O caráter híbrido das línguas que integram esse terceiro subgrupo é discutido pelos autores das gramáticas. Martins (2004) diz, por exemplo, que o dâw é uma língua isolanteanalítica, com pouca morfologia verbal, na qual categorias verbais, tais como pessoa, tempo, aspecto e número, são, em geral, indicadas por palavras gramaticais e morfemas que podem ocorrer tanto como forma independente quanto como sufixos. Tal característica favorece, pois, a expressão do argumento sujeito mais por meio de formas pronominais, já que a morfologia verbal, por ser mais sintética, tende a inibir a expressão da informação de pessoa também por meio de afixo verbal.

Alíngua ingarikó, por sua vez, apesar de ser classificada como aglutinante, que tenderia a favorecer a ocorrência de relações de maior opacidade entre os níveis de organização da linguagem, pode, segundo Sousa Cruz (2005), ser alocada entre as línguas polissintéticas e isolantes, pois também apresenta algumas palavras livres na morfossintaxe, o que, por sua vez, levaria essas línguas a codificar a categoria de pessoa de forma transparente, utilizando uma forma ou outra para marcar o sujeito. Ferreira (2005) assinala que algo semelhante ocorre com a língua matis, que, por apresentar partículas e advérbios como formas independentes em termos morfossintáticos, pode ser "considerada intermediária entre polissintética e isolante" (Ferreira 2005: 43).

Conforme afirma Araújo (2004), o sabanê também é uma língua aglutinante, mas se diferencia das demais línguas da família nambikwara, já que "as raízes nominais em sabanê normalmente têm duas ou mais sílabas, enquanto as outras línguas da família nambikwara, em geral, polissintéticas, possuem raízes monossilábicas" (Araújo 2004: 214, tradução nossa). Já a língua shanenawa é predominantemente aglutinante, mas apresenta também sufixos flexionais e derivacionais. A língua kamaiurá é classificada por Seki (2000) como uma língua aglutinativa-fusionante. Assim, o comportamento atípico das línguas que compõem este terceiro subgrupo, em termos de formulação e codificação das categorias gramaticais, poderia explicar, inicialmente, o fato de essas línguas apresentarem um funcionamento similar em relação à expressão do argumento sujeito, isto é, de marcar a informação de pessoa apenas uma única vez.

Enfim, as línguas indígenas desse subgrupo são mais transparentes que as línguas dos dois outros justamente porque mantêm, entre os níveis interpessoal e representacional, uma relação de um-para-um entre as respectivas unidades. 


\subsection{Relações de transparência e opacidade entre os níveis interpessoal e representacional na expressão de argumento sujeito}

Como o fenômeno de referência cruzada envolve dois subatos referenciais no nível interpessoal, que são designados no nível representacional como um indivíduo, haverá sempre, entre os dois níveis, uma relação de opacidade (dois-para-um). Esse tipo de operação é definido por Leufkens (2013) e Hengeveld e Leufkens (inédito) como redundância, exatamente porque viola a relação de transparência de um-para-um entre significado e forma, em que bastaria um subato referencial para indicar o sujeito.

O exemplo, a seguir, da língua Kwaza, reapresentado aqui com nova numeração, ilustra a relação de opacidade promovida pelo fenômeno de referência cruzada:

(10) Kwaza (Voort 2004: 244)

tx'ana cu'cu-a-re

nós.INCL pisar-1PL-INTER

'Somos nós que estamos caminhando (na foto)?'

As figuras 8 e 9 mostram como se processa a opacidade entre NI, NR e NM quanto à expressão e codificação do argumento sujeito na língua em questão:

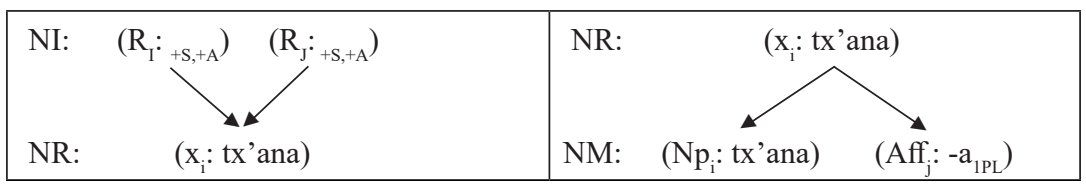

Figura 8: Relação de opacidade entre

Figura 9: Relação de opacidade entre

NI e NR no tocante à expressão de sujeito

NR e NM no tocante à codificação de sujeito

Fonte: Dados próprios da pesquisa.

Todas as demais línguas indígenas que compõem o primeiro subgrupo apresentam o mesmo modo de equacionamento das relações de opacidade entre os níveis interpessoal e representacional, com relação ao fenômeno de referência cruzada.

Por outro lado, quando o sujeito não é expresso nem lexical nem gramaticalmente, ou então quando a marcação de pessoa no verbo é a única forma disponível para esse fim, como é o caso de algumas línguas que integram esse primeiro subgrupo, parece que o mais correto é classificar essas ocorrências como concordância contextual, pois a expressão ou não do argumento sujeito é regida por fatores pragmáticos. Em outras palavras, quando o sujeito pronominal exerce a função de tópico dado, essa marcação de pessoa não precisa existir, pois a informação de sujeito pode ser recuperada pelo contexto, ao passo que quando o sujeito pronominal exerce a função pragmática de tópico ou foco, então ele passa a ser expresso lexicalmente, uma vez que exerce papel importante na relação de contraste com outro elemento:

(11) Matis (Ferreira 2016: 388)

$\begin{array}{lll}\varnothing(\mathrm{i}) & \text { unkin } & \text { tonka-a-s(i) } \\ \text { 3SG } & \text { porquinho } & \text { matar.com.arma-RECPST-3.EXP }\end{array}$

'Ele(a) matou o porquinho.' 
Como se pode verificar, em (11), o sujeito da oração em matis, nos casos de terceira pessoa do singular/plural, não é marcado foneticamente, o que significa, pelo menos nossa interpretação, que a identificação da referência, nesses contextos, mantém uma forte correlação com o contexto, tendo em vista que a não-marcação do argumento sujeito de terceira pessoa do singular serve também para a terceira pessoa do plural. No caso do português, por exemplo, quando a informação de pessoa (sujeito) já foi explicitada na interação, constituindo um tópico dado em termos pragmáticos, que pode ser recuperado no contexto, o argumento não precisa ser expresso lexicalmente ou gramaticalmente. Entretanto, em contextos de ambiguidade ou de tópico contrastivo, o argumento sujeito é expresso pelo menos pronominalmente, como em (5) e (6).

Segundo Hengeveld (2012), a ausência de expressão lexical/pronominal do argumento sujeito pode também ser decorrente do fato de o afixo verbal ser referencial por si só ou, então, por conta da própria referencialidade (Bickel, 2003) de certos elementos que, por serem amplamente conhecidos no processo de interação, podem ser facilmente recuperados no contexto. Trata-se de um fenômeno que Hengeveld (2012) prefere analisar como concordância contextual, e que pode, segundo o autor, ocorrer em uma mesma língua que tem referência cruzada.

Outra situação se dá quando a marcação de sujeito é realizada nas línguas indígenas a partir de um único dispositivo, que pode ser lexical ou gramatical. Quando isso ocorre, dizemos que as línguas [dâw, inagarikó, matis, sabanê, shanenawa, matsés, kaiowá e kamaiurá] possuem um sistema de referência simples, ${ }^{10}$ uma vez que há um único subato referencial no nível interpessoal que corresponde a um indivíduo no nível representacional, estabelecendo, assim, uma relação de transparência entre os níveis:

(12) Shanenawa (Cândido 2004: 118)
in istuku- $\varnothing$
$p i-i-m a-k i$
1SG macaco-ABS comer-NONPST-NEG-DECL
'Eu não como macaco.'

As figuras 10 e 11 mostram como se dá a relação de transparência entre os níveis interpessoal e Representacional quanto à expressão/codificação de sujeito em shanenawa:

\begin{tabular}{|lc|lc|}
\hline NI: & $\left(\mathrm{R}_{\mathrm{I}}:{ }_{+\mathrm{S},-\mathrm{A}}\right)$ & $\mathrm{NR}:$ & $\left(\mathrm{x}_{\mathrm{i}}:-\mathrm{in}\right)$ \\
& $\left.\mathrm{NR}_{\mathrm{i}}: \mathrm{in}\right)$ & $\mathrm{NM}:$ & $\left(\mathrm{Np}_{\mathrm{i}}:-\mathrm{in}_{1 \mathrm{SG}}\right)$ \\
\hline
\end{tabular}

Figura 10: Relação de transparência entre NI e NR no tocante à expressão de sujeito

Figura 11: Relação de transparência entre NR e NM no tocante à codificação de sujeito

Fonte: Dados próprios da pesquisa. apêndice 3 .

${ }^{10}$ Para mais informações e dados de línguas da amostra que apresentam referência simples, ver o 


\subsection{Relações de transparência/opacidade no nível morfossintático}

Como vimos, há línguas que não apresentam sistema de referência cruzada, mas sim sistema de concordância oracional, que ocorre quando a informação de sujeito lexical é copiada para outros componentes da oração. Isso se deve ao fato de ser a concordância oracional um fenômeno com motivação exclusivamente formal.

O exemplo (13), do kanoê, ilustra esse tipo de opacidade:

(13) Kanoê (Bacelar 2004: 171)

$\begin{array}{lll}\text { aj } & \text { i-pateñu } & \text { e-re } \\ \text { 1SG } & \text { 1-conhecer } & \text { DECL-AUX } \\ \text { 'Eu conheço.' } & \end{array}$

A figura 12 mostra como se processa a relação de opacidade entre as camadas do nível morfossintático com relação à codificação de sujeito em matsés:

NM: $\left(\mathrm{Np}_{\mathrm{i}}: 1 . \mathrm{SG}\left(\mathrm{Np}_{\mathrm{i}}\right)\right)_{\mathrm{Sbj}} \longrightarrow\left(\mathrm{Np}_{\mathrm{i}}: 1 . \mathrm{SG}\left(\mathrm{Np}_{\mathrm{i}}\right)\right)_{\mathrm{Sbj}}\left(\mathrm{Aff}_{\mathrm{i}}:<1 . \mathrm{SG}>\left(\mathrm{Aff}_{\mathrm{i}}\right)\right)$

Figura 12: Relação de opacidade entre as camadas do NM quanto à codificação de sujeito

Fonte: Dados próprios da pesquisa.

Tendo analisado as relações de transparência e opacidade entre os níveis de organização da GDF, com relação à expressão e codificação de sujeito nas línguas da amostra, passamos, agora, à discussão da ordenação dos marcadores.

\subsection{Ordenação dos marcadores de referência e dos marcadores de concordância}

Levando em consideração os aspectos teóricos discutidos e as questões de análise apresentadas, é possível, agora, verificar se são ou não confirmadas, nos dados analisados neste estudo, as previsões lançadas por Hengeveld (2012) com relação à ordenação dos marcadores de referência e dos marcadores de concordância quanto ao predicado. Para o autor, em conformidade com a proposta de Bybee (1985), se é verdade que os marcadores de pessoa no verbo podem ser referenciais por si sós, e que por isso a expressão lexical do argumento sujeito é opcional na estrutura oracional, então é esperado, em termos de ordenação morfossintática, que esses marcadores, por serem plenos de conteúdo, ocupem posições sintáticas mais próximas ao predicado, colocando-se sempre antes das categorias TAM, como em (14):

(14) Kwaza (Voort 2004: 244)

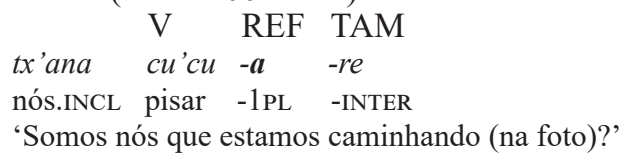


Por outro lado, se é também verdade que os marcadores de pessoa no verbo podem ser somente de concordância oracional, e que, por isso, a dupla marcação (pronominal e afixo verbal) de pessoa é sempre obrigatória na oração, então também é esperado, em termos de ordenação morfossintática, que esses marcadores, por serem apenas uma cópia de informação de pessoa expressa pronominalmente em outras unidades morfossintáticas, ocupem posições sintáticas mais externas ao predicado, imediatamente antes ou depois das categorias TAM, como em (15) e (16):

(15) Kanoê (Bacelar 2004: 216)

$\begin{array}{lllll} & & \text { AGR } & \text { TAM } & \text { V } \\ a j \quad j a & \tilde{\boldsymbol{o}} & -e & -r e \\ \text { 1sG querer } & \text { 1SG } & \text {-DECL } & \text {-AUX } \\ \text { 'Eu quero.' } & & & \end{array}$

(16) Kaiowá (Cardoso 2008: 74)

$\begin{array}{llll} & \text { AGR } & \text { V } & \text { TAM } \\ \text { hape } & \text { i-hu?u } & & \text { kuri } \\ \text { 3SG } & \text { 3-tossir } & & \text { PST }\end{array}$

'Ele tossiu.'

A tabela 2, abaixo, ilustra os padrões possíveis de ordenação de marcadores referenciais de pessoa encontrados na amostra de línguas indígenas analisadas:

Tabela 2: Padrões de ordenação dos marcadores referenciais na amostra de línguas

\begin{tabular}{l|l}
\hline LÍNGUAS & ORDENAÇÃO DOS MARCADORES \\
\hline kwaza, kotiria & V-REF-TAM \\
\hline (apinajé), xavante & TAM-REF-V \\
\hline--- & TAM-V-REF \\
\hline jarawara, tariana, apurinã, ingarikó & REF-V-TAM \\
\hline--- & *V-TAM-REF \\
\hline--- & *REF-TAM-V \\
\hline
\end{tabular}

Como se vê, as ordenações de marcadores de pessoa identificadas nas línguas da amostra demonstram que as previsões de Hengeveld (2012) acerca do posicionamento de marcadores referenciais de pessoa são, em tese, confirmadas neste estudo, uma vez que, quando o afixo verbal é referencial por natureza, os dados mostram que ele tende a se posicionar próximo do verbo, pelo fato de ser um elemento pleno de conteúdo. Não encontramos, como previsto pelo autor, casos de marcadores referenciais que seguissem o seguinte padrão de ordenação: V-TAM-REF ou REF-TAM-V. Os casos representados por REF-V-TAM, apesar de não violarem totalmente a expectativa do autor, não permitem avaliar as relações de escopo entre REF e os demais marcadores TAM.

A tabela 3 trata da ordenação dos marcadores de concordância oracional: 
LIAMES 17(2)

Tabela 3: Padrões de ordenação dos marcadores de concordância oracional na amostra de línguas

\begin{tabular}{l|l}
\hline LÍNGUAS & ORDENAÇÃO DOS MARCADORES \\
\hline kanoê & AGR-TAM-V \\
\hline kaiowá & AGR-V-TAM \\
\hline-- & TAM-V-AGR \\
\hline--- & *V-AGR-TAM \\
\hline--- & *TAM-AGR-V \\
\hline
\end{tabular}

Em todos os exemplos analisados, quando a marcação de pessoa é somente uma cópia de informação de outra unidade morfossintática, o que configura a concordância oracional, o marcador de pessoa se colocará sempre distante do predicado, aparecendo depois dos marcadores de tempo, aspecto e modo, como mostra a tabela 3. Ainda, como esperado, não encontramos nenhum dado com os seguintes padrões de ordenação nas línguas da amostra: V-AGR-TAM ou TAM-AGR-V, pois casos como esses violariam as condições esperadas de ordenação desses marcadores, conforme já foi discutido. Segundo Bybee (1985), essa ordenação reflete a distância em que o significado do afixo verbal afeta o significado do verbo, no sentido de que o que é mais importante e necessário tende a se colocar mais próximo da base, ao passo que o que é importante, porém, opcional ou de menor impacto, tende a se colocar mais distante da base.

Em suma, vale dizer que as tabelas apresentadas acima ilustram os padrões predominantes encontrados nas línguas. Isso não significa dizer que elas não apresentam outras possibilidades de ordenação dos marcadores de pessoa, tempo, aspecto e modo, até porque, a depender do tipo de verbo, intransitivo ou transitivo, a língua pode apresentar mais de uma possibilidade de ordenação desses marcadores de pessoa, ou até mesmo pode apresentar os dois tipos de fenômenos: referência cruzada e concordância.

\section{Generalizações e considerações finais}

A observação desses diferentes sistemas de marcação de pessoa permitiu distinguir, em nossa análise, três subgrupos de línguas indígenas na amostra: (i) as que apresentam sistema de referência cruzada (apinajé, apurinã, jarawara, kotiria, kwaza, tariana e xavante), (ii) as que apresentam sistema de concordância oracional (kanoê, kaiowá e matsés), e (iii) as que não apresentam nem referência cruzada nem concordância oracional (dâw, ingarikó, matis, sabanê, shanenawa e kamaiurá).

As línguas que compõem o primeiro e o segundo subgrupos são opacas, ou porque mantêm uma relação de dois-para-um entre forma e significado (no caso da referência cruzada) ou porque mantêm uma relação de um-para-dois entre formas no nível morfossintático (no caso da concordância oracional). Já as línguas indígenas que integram o último grupo são as mais transparentes da amostra, pois elas mantêm sempre uma relação de um-para-um entre as unidades dos níveis interpessoal e representacional.

O quadro 2 ilustra a correlação entre os agrupamentos de línguas indígenas da amostra, tipos de relação entre significado e forma e graus de transparência: 
Quadro 2: Correlação entre grupos de línguas da amostra, tipos de relação entre significado e forma e graus de transparência

\begin{tabular}{|l|l|l|}
\hline $\begin{array}{l}\text { kaiowá, matsés, dâw, } \\
\text { ingarikó, kamaiurá, matis, } \\
\text { sabanê, shanenawa }\end{array}$ & $\begin{array}{l}\text { apinajé, apurinã, jarawara, } \\
\text { kotiria, kwaza, tariana, matsés, } \\
\text { kaiowá, kamaiurá, xavante }\end{array}$ & Kanoê e kaiowá \\
\hline referência simples & referência cruzada & concordância oracional \\
\hline $\begin{array}{l}\text { relação de um-para-um } \\
\text { entre significado e forma }\end{array}$ & $\begin{array}{l}\text { relação de dois-para-um entre } \\
\text { significado e forma }\end{array}$ & $\begin{array}{l}\text { relação de um-para-dois entre } \\
\text { referente e múltiplas formas }\end{array}$ \\
\hline [transparência] & [opacidade] & [opacidade] \\
\hline
\end{tabular}

A característica comum entre as línguas mais transparentes é a de que todas apresentam uma morfologia mista, que mescla traços de morfologia aglutinante e traços de morfologia isolante, o que, segundo Hengeveld e Leufkens (inédito), explicaria a tendência para o estabelecimento de relações de um-para-um entre os níveis interpessoal e representacional, como se vê no quadro 2. Já as línguas dos dois outros subgrupos apresentam, com maior frequência, uma morfologia aglutinante, o que também explicaria, consoante os autores, a incidência maior de opacidade entre os níveis.

O quadro 3, abaixo, explicita as formas possíveis de marcação de pessoa e os níveis de organização envolvidos em cada um dos fenômenos:

Quadro 3: Sistemas de marcação de pessoa e níveis de operação da GDF

\begin{tabular}{l|l|l|l}
\hline $\begin{array}{l}\text { Sistema de } \\
\text { marcação }\end{array}$ & $\begin{array}{l}\text { marca de pessoa no verbo } \\
\text { nunca coocorre com a } \\
\text { marcação lexical de sujeito }\end{array}$ & $\begin{array}{l}\text { marca de pessoa no verbo } \\
\text { opcionalmente coocorre } \\
\text { com a marcação lexical } \\
\text { de sujeito }\end{array}$ & $\begin{array}{l}\text { marca de pessoa no verbo } \\
\text { sempre coocorre com } \\
\text { a marcação lexical de } \\
\text { sujeito }\end{array}$ \\
\hline $\begin{array}{l}\text { Tipo de } \\
\text { marcador }\end{array}$ & marcador único de referência & $\begin{array}{l}\text { marcador referencial de } \\
\text { aposição }\end{array}$ & $\begin{array}{l}\text { marcador de concordância } \\
\text { sintática }\end{array}$ \\
\hline Fenômeno & referência simples & referência cruzada & concordância oracional \\
\hline $\begin{array}{l}\text { Níveis } \\
\text { envolvidos }\end{array}$ & $\begin{array}{l}\text { nível interpessoal - nível } \\
\text { representacional }\end{array}$ & $\begin{array}{l}\text { nível interpessoal - nível } \\
\text { representacional }\end{array}$ & nível morfossintático \\
\hline Relação & transparente & opaco & opaco \\
\hline
\end{tabular}

Três critérios que se colocam como os mais relevantes para a distinção entre referência simples, referência cruzada e concordância oracional nas línguas indígenas da amostra são: a coocorrência da marca de pessoa no verbo com a expressão lexical do sujeito, ordenação dos marcadores de pessoa e os níveis de operação de cada um dos fenômenos analisados. Os casos de referência simples e referência cruzada ocorrem entre os níveis interpessoal e representacional, ao passo que os casos de concordância oracional ocorrem apenas entre as camadas do nível morfossintático.

O quadro 4 ilustra, com base em Hengeveld (2011) e Leufkens (2013), a hierarquia de resistência à ocorrência dos fenômenos analisados nas línguas indígenas: 
Quadro 4: Hierarquia de resistência à ocorrência de fenômenos opacos nas línguas da amostra

\begin{tabular}{l|l}
\hline CONCORDÂNCIA ORACIONAL & Alta \\
\hline [kanoê, kaiowá] & $\begin{array}{l}\text { Grau de resistência de } \\
\text { ocorrência nas línguas }\end{array}$ \\
\hline REFERÊNCIA CRUZADA & Baixa \\
\hline [apinajé, jarawara, kotiria, kwaza, tariana, xavante, apurinã] & Baix \\
\hline
\end{tabular}

O quadro 4 mostra que ambos os fenômenos, concordância oracional e referência cruzada, são opacos e podem ocorrer nas línguas; entretanto, a hierarquia nele expressa mostra também que o fenômeno da concordância oracional, situado no topo do quadro, ocorre com baixa frequência, isto é, possui alta resistência de ocorrência nas línguas, ao passo que o fenômeno da referência cruzada, situado na base do quadro, tende a ocorrer com maior frequência nas línguas indígenas, ou seja, possui baixa resistência de ocorrência nas línguas investigadas.

Em outras palavras, o que esse quadro ilustra é que, se for para expressar o argumento sujeito de forma duplamente marcada, gerando, assim, uma relação de opacidade, as línguas da amostra tendem a optar mais por um sistema de dupla marcação opcional, quando as duas marcas de pessoa são referenciais, do que por um sistema de dupla marcação obrigatória, quando a marca de pessoa no verbo constitui uma cópia obrigatória da informação de pessoa expressa pronominalmente. Uma evidência de que existe tal restrição ou resistência é o fato de termos encontrado apenas duas línguas na amostra que apresentam concordância oracional, enquanto o número de línguas que apresentam referência cruzada é muito mais expressivo (dez línguas), o que representa mais da metade do total de línguas analisadas (10 do total de 16 línguas).

Por fim, foi ainda possível confirmar uma das previsões de Hengeveld (2012) acerca da preferência de ordenação dos marcadores referencias e dos marcadores de concordância oracional quanto às demais categorias do verbo (TAM): verificamos que, quando o marcador de pessoa é referencial, munido de conteúdo pleno, ele aparecerá mais próximo à base verbal, colocando-se sob o escopo das categorias TAM, como em V-REF-TAM, ao passo que, quando o marcador de pessoa é apenas de concordância, ele ocupará, em termos de ordenação morfossintática, uma posição externa ao verbo, como em V-TAM-AGR, exatamente porque não afeta o seu significado.

\section{$\overline{\text { Referências }}$}

Aikhenvald, Alexandra (2003). A grammar of Tariana, from Northwest Amazonia. Cambridge: Cambridge University Press.

Araújo, Gabriel Antunes (2004). A grammar of Sabanê: a nambikwaran language (Ph.D. dissertation). Amsterdam: Vrije Universiteit. 
Bacelar, Laércio Nora (2004). Gramática da língua Kanoê (Ph.D. dissertation). Nijmegen: Katholieke Universiteit Nijmegen.

Bybee, Joan (1985). Morphology. Philadelphia: John Benjamins.

Cândido, Gláucia Vieira (2004). Descrição morfossintática da língua Shanenawa (Tese de doutorado em linguística). Campinas: UNICAMP/IEL.

Cardoso, Valéria Faria (2008). Aspectos morfossintáticos da lingua Kaiowá (Guarani) (Tese doutorado em linguística). Campinas: UNICAMP/IEL.

Dik, Simon (1989). The theory of functional grammar. Dordrecht: Foris Publication.

Dik, Simon (1997). The theory of functional grammar: Part II: Complex and derived constructions. New York: Mouton de Gruyter.

Dixon, R. M. W. (2004). The Jarawara language of Southern Amazonia. Oxford: Oxford University Press.

Facundes, Sidney da Silva (2000). The language of the Apurinã people of Brazil (Ph.D. dissertation). Buffalo: University of New York.

Ferreira, Rogério Vicente (2005). Língua Matis (Pano): uma descrição gramatical (Tese de doutorado em linguística). Campinas: UNICAMP/IEL.

Fleck, David W. (2003). A grammar of Matses (Ph.D. dissertation). Houston: Texas: Rice University.

Fleck, David W. (2005). Ergatividade em Matsés (Pano). LIAMES-Línguas Indígenas Americanas 5: 87-109. Disponível em: https://periodicos.sbu.unicamp.br/ojs/index.php/liames/article/view/1440/1430

Hengeveld, Kees (2011). Transparency in functional discourse grammar. Linguistics in Amsterdam 4: 1-22.

Hengeveld, Kees (2012). Referential markers and agreement markers in functional discourse grammar. Language Sciences 34: 468-479.

Hengeveld, Kees; Leufkens, Sterre (inédito). Transparent and non-transparent languages. Amsterdam Center for Language and Communication.

Hengeveld, Kees; Mackenzie, Lachan (2008). Functional discourse grammar: a typologically-based theory of language structure. Oxford: Oxford University Press.

Jansen, W. (2011). Esperanto: a language made transparent? Linguistics in Amsterdam 4: 57-74.

Leipzig Glossing Rules (2016). Conventions for interlinear morpheme-by-morpheme glosses. Disponível em: www.eva.mpg.de/lingua/resources/glossing-rules.php. Acesso em: 15/08/2016.

Leufkens, Sterre (2013). The transparency of creoles. Journal of Pidgin and Creole Languages 28(2): 323-362.

Leufkens, Sterre (2015). The transparency in language: a typological study. Utrecht: LOT Publications.

Martins, Silvana Andrade (2004). Fonologia e gramática Dâw (Tese de doutorado). Amsterdam: Vrije Universiteit Amsterdam.

Mulder, Mijke (2013). Transparency in modern Hebrew: a functional discourse grammar analysis. Linguistics in Amsterdam 6: 1-27. 
Oliveira, Christiane Cunha de (2005). The language of the Apinajé people of Central Brazil (Ph.D. dissertation). University of Oregon.

Oliveira, Christiane Cunha de (2014). A codificação das relações gramaticais nos complementos oracionais do Apinajé. Signótica 26(2): 287-308.

Oliveira, Rosana Costa de Oliveira (2007). Morfologia e sintaxe da língua Xavante (Tese de doutorado em linguística). Rio de Janeiro: Faculdade de Letras-UFRJ.

Öztürk, Balkız (2002). Turkish as a non-pro-drop language. In Eser Erguvanli Taylan (ed.). The verb in Turkish (Linguistics Today 44), pp. 239-259. Amsterdam: John Benjamins Publishing Company

Seki, Lucy (2000). Gramática do Kamaiurá: língua tupi-guarani do Alto Xingu. Campinas: Editora da UNICAMP.

Siewierska, Anna (1999). From anaphoric pronoun to grammatical agreement marker: why objects don't make it. Folia Linguistica 33(2): 225-251.

Sousa Cruz, Maria Odileiz (2005). Fonologia e gramática Ingarikó (Ka?pon - Brasil) (Tese de doutorado). Amsterdam: Vrije Universiteit.

Stenzel, Kristine (2013). A reference grammar of Kotiria (Wanano). Lincoln: University of Nebraska Press.

Voort, Hein van der (2004). A grammar of Kwaza (Ph.D. dissertation). Leiden: University of Leiden. 


\section{Apêndice 1. Casos de referência cruzada}

Entre as línguas indígenas do primeiro grupo estão apinajé, jarawara, kotiria, kwaza, tariana, xavante, apurinã, kaiowá, matsés e kamaiurá. Nessas línguas, como vimos, a marcação de pessoa no verbo coocorre com a expressão pronominal do mesmo argumento na oração, o que também é conhecido como concordância de pessoa. Os exemplos de (1) a (10) ilustram a ocorrência de referência cruzada nessas línguas:

(1) Apinajé (Oliveira 2005: 161)

$\begin{array}{llll}\text { kot } & \text { paj } & \text { arĩ } & \text { ic-krĩ } \\ \text { IRLS } & \text { 1SG.IRLS } & \text { ficar } & 1 \text { 1sG-sentar }\end{array}$

'Eu ficarei sentado.'

(2) Jarawara (Dixon 2004: 82)

jao o-koba-tee ama o-ke

preguiça.OBJ.T 1sG.SUBJ.T-comer-HAB EXT 1SG-DECL.F

'Eu costumo comer preguiça.'

(3) Kotiria (Stenzel 2013: 315)

yu'ú $\sim$ bó $\sim$ baká+ri+ro-pu hí-ha

1SG Mõ vila+NOM+SG-LOC COP-VIS.IMPERF.1

'Eu sou de Mõ.'

(4) Kwaza (Voort 2004: 244)

tx'ana cu'cu-a-re

nós.INCL pisar-1PL-INTER

'Somos nós que estamos caminhando (na foto)?'

(5) Tariana (Aikhenvald 2003: 236)

nuha sirusi nu-walita nu-a

1SG cumatá-folhas 1SG-fazer.oferta 1SG-ir

'Eu estou fazendo uma oferta de cumatá de folhas.'

(6) Xavante (Oliveira 2007: 132)

o hã buru u ma Ø-romhu

3SG roça para 3SG/PST 3sG-trabalhar

'Ele trabalhou na roça.'

(7) Apurinã (Facundes 2000: 474)

pite n-atama-ta nota

2SG 1sG-ver-vBLz $1 \mathrm{sG}$

'Eu vi você.'

(8) Kaiowá (Cardoso 2008: 64)

fe a-wi?a

1SG 1sG-alegre

'Eu estou alegre' 
(9) Matsés (Fleck 2005: 92)

ubi ush-o-k

1 ABS dormir-PST- $1 / 2$

'Eu dormi.'

(10) Kamaiurá (Seki 2000: 68)

je='arnot we-ko-m

$1 \mathrm{sG}=$ ter saudade $1 \mathrm{sG}-\mathrm{COP}-\mathrm{G}$

'Eu fiquei com saudades.'

Em apinajé, no exemplo (1), a marca de pessoa no verbo "ic-" (eu) coocorre com a expressão lexical do argumento sujeito "paj” (eu), caracterizando, assim, um caso de referência cruzada, segundo Hengeveld $(2011,2012)$ e Leufkens (2013). O mesmo comportamento se observa nos dados das demais línguas listadas acima. Em jarawara, no exemplo (2), o prefixo verbal de primeira pessoa do singular "o-" é empregado juntamente com o pronome "o" (primeira pessoa do singular). O pronome sujeito de primeira pessoa do plural "yu'ú" (primeira pessoa do singular), em (3), coocorre com a marca de concordância "-ha" (primeira pessoa do singular) anexada ao verbo. No exemplo (4) do kwaza, a referência do pronome sujeito inclusivo "tx'ana" (nós inclusivo) é replicada na morfologia do verbo, a partir do uso do sufixo "-a" (primeira pessoa do plural). Em (5), o pronome de primeira pessoa do singular "nuha" (eu) da língua tariana coocorre com a expressão sufixal do argumento sujeito "nu-" (primeira pessoa do singular). Em xavante, no exemplo (6), o sujeito pronominal "o hã" (ele) é usado juntamente com a marca de terceira pessoa do singular "ø-" acrescida ao verbo. Em (7), da língua apurinã, a marca de primeira pessoa do singular "n-" prefixada ao verbo coocorre com a expressão lexical do argumento sujeito "nota" (você, segunda pessoa do singular). Em (8), o argumento sujeito é marcado em pelo pronome " $\mathrm{e}$ " e pelo prefixo verbal de pessoa "a-" (primeira pessoa do singular). Em (9), temos outro caso de dupla marcação do argumento sujeito em matsés: o pronome "ubi" (primeira pessoa do singular absolutivo) e o sufixo verbal de pessoa “-k". Por fim, em (10), temos outro caso de língua tupi-guarani, o kamaiurá, que possui características em comum no tocante à classificação de pronomes e clíticos pessoais em séries distintas: nesse exemplo, o argumento sujeito é duplamente marcado por meio do clítico pronominal "je=" (primeira pessoa do singular) e do prefixo subjetivo de primeira pessoa singular "we-", pertencente à série II da classe pronominal. Como em todos os exemplos listados, o sujeito é duplamente marcado na oração, as línguas indígenas são classificadas como opacas, uma vez que há dois subatos referenciais no nível interpessoal que correspondem a um mesmo indivíduo no nível representacional.

Segundo Hengeveld (2012), o que comprova a existência de referência cruzada em uma língua, como se vê nos exemplos acima, é a possibilidade de o sujeito ser codificado apenas pelo morfema verbal. Quando isso acontece, conforme mostram os exemplos a seguir, não há necessidade de o argumento sujeito ser expresso também em termos pronominais, fato que mostra que essas duas estratégias gramaticais constituem sistemas alternativos para marcação de sujeito nas línguas indígenas da amostra. 
(11) Apinajé (Oliveira 2005: 246)

a ic-pe kenkutã

$\operatorname{sim}$ 1SG-COP N.

'Sim, eu sou Kengutã.'

(12) Jarawara (Dixon 2004: 83)

jifo $\quad$ o-wa

lenha.OBJ.F 1sG.SUBJ.T-procurar+F

'Eu procuro lenha.'

(13) Kotiria (Stenzel 2013: 82)

da'ra- da wa'a-bo-ka

trabalhar-(1/2)PL ir-DUB-ASS.IMPF

'Poderemos ir trabalhar.'

(14) Kwaza (Voort 2004: 245)

lo'na 'je-da-ki

buraco cavar-1SG-DECL

'Eu cavei um buraco'

(15) Tariana (Aikhenvald 2003: 238)

du-bueta-daka

3sG.F-aprender-ainda

'Ela ainda está estudando.'

(16) Xavante (Oliveira 2007: 133)

buru u ma Ø-romhu

roça para 3sG/PST 3sG-trabalhar

'Ele trabalhou na roça'

(17) Apurinã (Facundes 2000: 242)

u-suka-pe

3SG.M-dar-PFTV

'Ele deu.'

(18) Kaiowá (Cardoso 2008: 39)

a-japo Se-r-oya

1SG-fazer 1sG-REL-casa

'(eu) faço minha casa.'

(19) Matsés (Fleck 2005: 92)

uşh-o-bi

dormir-PST-1s/o

'Dormi.'

(20) Kamaiurá (Seki 2000: 142)

o-'apyk o-'in

3SG-sentar 3-AUX

'Ele está sentado [em posição não estendida]' 
Como se verifica, em todos os exemplos acima, a marcação de pessoa no verbo, representada aqui pelos morfemas grafados em negrito, é referencial por si só, já que o argumento sujeito não precisa ser expresso lexicalmente, ou seja, o sistema de marcação do sujeito oracional nessas línguas indígenas é opcional, pode tanto ser expresso pela dupla marcação, quando o sujeito é expresso simultaneamente no verbo e na forma lexical, ou apenas por meio da expressão lexical ou então apenas por meio da marcação de sujeito na estrutura verbal (em termos de prefixos, infixos ou sufixos). Sendo assim, segundo Hengeveld (2012), quando a marcação do sujeito é opcional nas línguas, isto é, há mais de uma forma para marcar a categoria de pessoa, então, é possível dizer que elas apresentam um sistema de referência cruzada, caso contrário, se a dupla marcação do sujeito é sempre obrigatória na estrutura oracional, a tendência, conforme o autor, é a de que esse sistema seja mais bem classificado como um caso de concordância oracional.

Em (11), o prefixo "ic-" de primeira pessoa do singular, anexado ao verbo cópula "ser", é a única marca de pessoa disponível na oração, motivo pelo qual tal marca é definida, com base em Hengeveld (2011, 2012), Mulder (2011) e Leufkens (2013), como referencial por natureza, pois ela é suficiente para expressar o sujeito da oração. O mesmo ocorre em jarawara, em (12), tariana, em (15), xavante, em (16), apurinã, em (17), kaiowá, em (18), kamaiurá, em (20), em que, respectivamente, os prefixos verbais "ti-", de segunda pessoa do singular, "du-", de terceira do singular, "ø-", de terceira pessoa do singular, "u-", de terceira pessoa do singular, "a-", de primeira pessoa do singular, e prefixo "o-", de terceira pessoa do singular, são referenciais por si sós, uma vez que são os únicos dispositivos gramaticais utilizados nesses contextos das línguas para marcar o argumento sujeito. Já as línguas kotiria, em (13), kwaza, em (14), e matsés, em (19), empregam sufixos verbais para codificar a informação de pessoa. 
Apêndice 2. Casos de concordância oracional

Os exemplos, abaixo, ilustram casos de concordância oracional, que operam no nível morfossintático, em que a informação de pessoa, atrelada a um constituinte da oração (em geral, o pronome) é copiada em outros constituintes oracionais:

(21) Kanoê (Bacelar 2004: 171)

aj i-pateñu e-re

1SG 1-conhecer DECL-AUX

'Eu conheço.'

(Classe I: flexão prefixal de pessoa na cabeça verbal)

(22) Kanoê (Bacelar 2004: 173)

ojte ore-Ø-ry e-re

3PL cansar-3-REF DECL-AUX

'Eles estão cansados.' (Classe II: flexão pós-raiz verbal de pessoa)

(23) Kanoê (Bacelar 2004: 98)

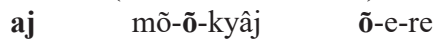

1SG dormir-1-olho 1SG-DECL-AUX

'Eu durmo.' (Lit. Eu estou dormindo) (Classe III: flexão de pessoa em TAM)

(24) Kaiowá (Cardoso 2008: 74)

ore ore $=r$-asẽ

nós.EXCL 1PL.EXCL $=$ REL-chorar

'Nós choramos.'

Em kanoê, a dupla marcação de sujeito é sempre obrigatória, como se vê em (23), em que sujeito pronominal "aj” (primeira pessoa do singular) é empregado juntamente com a marca de pessoa no verbo "õ-" (primeira pessoa do singular). De acordo com Hengeveld (2012: 474), sempre quando se verifica esse tipo de coocorrência, o fenômeno é classificado como concordância oracional ou concordância sintática. O próprio Bacelar, autor da gramática descritiva Kanoê, diz que "nomes e pronomes pessoais livres, na função de núcleo de sujeito, concordam por referência cruzada com pronominais flexionais presos, prefixais ou sufixais, na estrutura predicativa" (Bacelar 2001: 98), no entanto, em conformidade com a noção de referência cruzada aqui assumida, sabemos que os morfemas verbais empregados em Kanoê, como em (22), não são referenciais por si só, pois não ocorrem sozinhos.

O exemplo da língua kaiowá, em (24), mostra que o clítico pronominal "ore=", pertencente, segundo Cardoso (2008: 67), à série II, sempre coocorre com a marcação de pessoa também na forma pronominal "ore" (primeira pessoa do plural exclusiva), indicando, assim, que o argumento sujeito, em contextos que envolvem os clíticos pronominais da série II, é obrigatoriamente marcado no verbo e no pronome. Segundo Cardoso (comunicação pessoal), a marcação do argumento sujeito por meio de prefixos verbais (pertencentes à série I) é sempre obrigatória em kaiowá, porém, o pronome sujeito, nesse caso, é opcional, o que justifica o fato de essa língua também figurar no subgrupo de línguas com referência cruzada. No entanto, quando a expressão do argumento sujeito envolve os clíticos pronominais da série II, a dupla marcação de pessoa (clítico/afixo 
verbal e pronome sujeito) é sempre obrigatória, configurando, dessa forma, um caso de concordância oracional, fato que explica o porquê de essa língua também aparecer no subgrupo de línguas com concordância oracional, a exemplo do ocorre no francês. Assim, nesses casos, a relação de opacidade se processa no próprio nível morfossintático e não pode ser entendida como um caso de redundância, pois não envolve uma unidade de significado do nível representacional que é codificada no nível morfossintático por duas formas distintas, mas sim uma informação gramatical de pessoa que é copiada do sintagma nominal no verbo por meio de afixo/clítico. 


\section{Apêndice 3. Casos de referência simples}

Entre as línguas indígenas que não apresentam nem referência cruzada nem sistema de concordância oracional, mas sim um sistema de referência simples (única marcação de pessoa), estão dâw, inagarikó, matis, sabanê, shanenawa e kamaiurá. Como nessas línguas, o sujeito é, em geral, expresso lexicalmente (pronome), apresentando, portanto, um único marcador referencial (Hengeveld 2012: 474), elas são aqui classificadas como as mais transparentes da amostra analisada. Vejamos:

(25) Dâw (Martins 2004: 350)

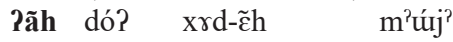

1SG MOV? passar-NEG 2SG.OBL

'Eu não vou levar você.'

(26) Ingarikó (Sousa Cruz 2005: 225; 367)
a. w-e?nepïrï- $\varnothing$
1SG-Sonhar-PRS
'Eu sonho.'
b. ka?pon wënë-?pï to? uya
pessoa matar-PST Pro:3PL ERG
'Eles mataram a pessoa'

(27) Matis (Ferreira 2005: 253)

ibi tşoda-n us-a-k

1SG.ABS chão-LOC dormir-RECPST-DECL

'Eu dormi no chão.'

(28) Sabanê (Araújo 2004: 156)

towali ilul-i-palisin-al-i

1SG.SUBJ comer-VS-DES-PRS-ASS

'Eu quero.'

(Resposta à pergunta: você quer comer?

(29) Shanenawa (Cândido 2004: 72)

in min-fi ka-a-ki

$1 \mathrm{SG} \quad$ 2SG-COM ir-PST-DECL

'Eu fui com você.'

(30) Kamaiurá (Seki 2000: 319)

yrypary-a a-pyhyk mokõj

cesta-N 1SG-pegar dois

'Eu pego duas cestas.'

(31) Matsés (Fleck 2005: 92)

uşh-e-bi

dormir-NPST-1s/o

'Vou dormir.' 
Em (25), (26b), (27), (28) e (29), o sujeito é expresso lexicalmente (por meio de pronomes de pessoa), conforme mostram os termos em negrito. Já nos exemplos (26a) e (30), o argumento sujeito é marcado gramaticalmente, por meio de prefixos anexados ao verbo. Já em (31), a informação de pessoa é marcada apenas no verbo por meio do sufixo "bi-". Esses exemplos ilustram os casos de línguas descritos por Hengeveld (2012) que não apresentam coocorrência de expressão lexical e expressão gramatical do sujeito, de modo que há uma única marcação de pessoa na oração e ela é referencial.

É possível estabelecer, nesse terceiro subgrupo de línguas, uma correlação, ainda que parcial, entre o tipo morfológico da língua e o seu grau de transparência, já que as línguas indígenas que compõem esse grupo apresentam, na sua maioria, uma morfologia mista, isto é, elas têm traços de morfologia aglutinante, mas também apresentam traços de morfologia isolante, o que poderia contribuir para o fato de essas línguas serem, entre todas aquelas analisadas, as mais transparentes da amostra. Mesmo nos casos que a língua é basicamente aglutinante, observa-se que a relação entre forma e sentido é quase sempre de um-para-um, o que novamente corrobora a nossa análise. 


\begin{tabular}{|c|c|}
\hline \multicolumn{2}{|c|}{ Abreviaturas - Questões teóricas } \\
\hline GDF & Gramática Discursivo-Funcional \\
\hline NI & Nível interpessoal \\
\hline NR & Nível representacional \\
\hline NM & Nível morfossintático \\
\hline NF & Nível fonológico \\
\hline SG & Singular \\
\hline PL & PluraL \\
\hline FUT & Futuro \\
\hline OBJ & Objeto \\
\hline DEF & Definido \\
\hline GF & Gramática funcional \\
\hline M & Movimento \\
\hline A & Ato discursivo \\
\hline ILL & Ilocucão \\
\hline $\mathrm{P}$ & Participante \\
\hline PS & Falante \\
\hline $\mathrm{P}_{\mathrm{A}}$ & Ouvinte \\
\hline $\mathrm{C}$ & Conteúdo comunicado \\
\hline $\mathrm{R}_{1}$ & Subato referencial \\
\hline $\mathrm{T}_{1}$ & Subato Atributivo \\
\hline $\mathrm{P}$ & Conteúdo proposicional \\
\hline EP & Episódio \\
\hline $\mathrm{E}$ & Estado-de-coisas \\
\hline $\mathrm{F}$ & Propriedade \\
\hline $\mathrm{X}$ & Indivíduo \\
\hline $\mathrm{P}^{2}$ & Posição secundária \\
\hline $\mathrm{P}^{\mathrm{F}}$ & Posição final \\
\hline $\mathrm{P}^{\mathrm{F}-1}$ & Posição situada 1 lugar antes da posição final \\
\hline $\mathrm{P}^{\mathrm{I}}$ & Posição inicial \\
\hline $\mathrm{P}^{\mathrm{M}}$ & Posição medial \\
\hline $\mathrm{P}^{\mathrm{M}-1}$ & Posição situada 1 lugar depois da posição medial \\
\hline $\mathrm{U}$ & Enunciado \\
\hline IP & Frase Entonacional \\
\hline PP & Frase Fonológica \\
\hline PW & Palavra Fonológica \\
\hline $\mathrm{F}$ & Pé \\
\hline $\mathrm{S}$ & Sílaba \\
\hline
\end{tabular}




\begin{tabular}{|c|c|}
\hline \multicolumn{2}{|c|}{ Abreviaturas - Glosas } \\
\hline 1 & Primeira pessoa \\
\hline 2 & Segunda pessoa \\
\hline 3 & Terceira pessoa \\
\hline $\mathrm{A} / \mathrm{O}$ & Sujeito transitivo/Objeto transitivo \\
\hline ABS & Absolutivo \\
\hline AGR & Afixo de concordância \\
\hline AOR & Aoristo \\
\hline ASS & Assertivo \\
\hline AUX & Auxiliar \\
\hline $\mathrm{C}$ & Consoante \\
\hline $\mathrm{COM}$ & Comissivo \\
\hline COP & Cópula \\
\hline DECL & Declarativo \\
\hline DES & Desiderativo \\
\hline DIM & Diminutivo \\
\hline DUB & Dubidativo \\
\hline EMPH & Ênfase \\
\hline ERG & Ergativo \\
\hline EXCL & Exclusivo \\
\hline EXP & Experencial \\
\hline EXT & Extensão \\
\hline $\mathrm{F}$ & Feminino \\
\hline G & Modo Gerúndio \\
\hline HAB & Habitual \\
\hline IMM & Imediato \\
\hline IMPERF & Imperfectivo \\
\hline IMPF & Imperfeito \\
\hline INCL & Inclusivo \\
\hline INS & Instrumento \\
\hline INTER & Interrogativo \\
\hline IRLS & Irrealis \\
\hline LOC & Locativo \\
\hline M & Masculino \\
\hline MOV & Movimento \\
\hline N. & Nome Próprio \\
\hline NEG & Negação \\
\hline NMLZ & Nominalizador \\
\hline NOM & Nominativo \\
\hline NONPST & Não-passado \\
\hline $\mathrm{NP}$ & Sintagma nominal \\
\hline NPST & Não-passado \\
\hline OBJ.T & Objeto transitivo \\
\hline OBL & Oblíquo \\
\hline
\end{tabular}




\begin{tabular}{ll}
\hline PAS & Passivo \\
PFTV & Perfectivo \\
PL & Plural \\
PONT & Pontual \\
POS & Positivo \\
PROGR & Progressivo \\
PRS & Presente \\
PST & Passado \\
REC & Recipiente \\
RECPST & Passado recente \\
REF & Afixo de referência \\
REL & Relacional \\
RLS & Realis \\
S & Argumento de verbo intransitivo \\
S/O & Sujeito/objeto (Matsés) \\
SG & Singular \\
SIM & Simultâneo \\
SUBJ & Subjuntivo \\
SUBJ.T & Sujeito Transitivo \\
TAM & Tempo, aspecto e modo \\
V & Valência \\
VBLZ & Verbalizador \\
VIS & Visual \\
VOL & Volitivo \\
VS & Sufixo verbal \\
\end{tabular}

Recebido 19/5/2017

Versão revista 1: 11/10/2017

Versão revista 2: 18/10/2017

Aceito: 27/10/2017. 